\title{
Cost evaluation of foam bitumen and other stabilisation alternatives
}

\author{
MOFREH F. SALEH*
}

Department of Civil Engineering, University of Canterbury, Christchurch, New Zealand

(Received 31 May 2005; revised 29 August 2006; in final form 29 September 2006)

As the demand for a cost efficient and environmental friendly pavement stabilisation method increases, so has foamed bitumen stabilisation for unbound granular pavement layers started to gain broad acceptance worldwide. The work forms part of a larger project aimed at investigating the feasibility and potential applications of the foamed bitumen stabilisation technique in order to speed up its adoption in New Zealand.

In this paper, a cost-analysis exercise comparing the capital cost of eight base course stabilisation alternatives in addition to hot mix asphalt (HMA) alternative was made. Cement, lime and foam bitumen stabilisation versus HMA design alternatives were compared. The foam stabilised mix represents a high quality base course material stabilised with $2.0 \%$ cement and $3.5 \%$ foam bitumen. The results of this analysis showed that foam bitumen stabilisation using high quality aggregates and about $2 \%$ cement is competitive compared to unbound materials because a reduced layer thickness is required.

Keywords: Foam bitumen; Lime; Cement; Stabilisation

\section{Introduction}

Pavement stabilisation has been commonplace in New Zealand since 1960s. Although bitumen (using an asphalt plant) and bitumen emulsion have been used for pavement stabilisation, the most common methods are lime and cement stabilisation (Hudson 1996). Although foamed bitumen stabilization is gaining wide acceptance in several countries around the world, it has not been widely practiced in New Zealand. The cost effectiveness of foamed bitumen stabilisation in New Zealand compared to other stabilisation techniques will depend, to some degree, on specific projects. In general terms, binder costs are typically half of the total project costs (Australian Stabilisation Industry Association, ASIA 2000). In New Zealand, the cost of bitumen is typically 3-4 times that of cement or lime, therefore, on that basis (assuming comparable lifetimes) lime or cement stabilisation would be favoured. However, one of the key advantages of foamed bitumen stabilisation, in contrast to lime- or cement-stabilised pavements, is that they can be trafficked almost immediately after compaction. On highly trafficked urban roads and motorways, the requirement to minimise traffic delays governs the construction process, and prolonged road closures (with the associated costs to road users) cannot be tolerated. On highly trafficked roads, the cost of traffic management is about $30 \%$ of the total capital cost of the project. In these instances, the use of cement or lime stabilisation could be disadvantageous. In addition to the reduction in traffic delay, foamed bitumen stabilisation is likely to become more common in the future as sources of good quality aggregates (particularly in the Auckland area) become scarcer and attention turns to the use of more marginal materials.

Both cement and lime can contaminate the ground water by raising the $\mathrm{pH}$ value, and this is a problem in urban areas. Contrary to lime and cement, foamed bitumen is environmentally friendly and it does not cause any contamination to the surrounding area. Furthermore, comparing foamed bitumen to cutbacks or even emulsions, foamed bitumen is a clean alternative and does not cause any leakage of kerosene or emulsifying agents into the surrounding environment. Such environmental advantages are vital but hard to quantify in the economic analysis.

*Tel.: + 643-3642987. Fax: + 643-3642758. Email: mofreh.saleh@canterbury.ac.nz 


\section{Background}

Adding a small amount of water or steam (about 2\%) to hot bitumen results in the formation of a foam that expands many times the original volume of the bitumen (Csanyi 1957, 1962; Ruckel et al. 1983). The low viscosity of the foam allows it to mix easily with aggregates. The foam breaks and preferentially coats the fine aggregate particles in the mix. Foamed bitumen mixes are distinctive in that, as opposed to hot mix and emulsion mixes; large aggregate particles are only partially coated. The bitumen coated fines form a mortar that binds the mixture together.

Foamed bitumen can be used with a wide range of aggregate types (including marginal materials with high plasticity indices) and with cold, moist aggregates (Muthen 1999). In fact, optimum moisture content is essential for good dispersion of the foam in the mix. Fines $(<75 \mu \mathrm{m})$ content greatly affects mix strength and should exceed $5 \%$ of the volume of the mix (Bowering and Martin 1976; Jenkins et al. 1999). Bitumen content usually lies in the range of $2-5 \%$ and needs to be optimized depending on the fines content.

Foamed bitumen stabilization increases the resilient modulus value of the mix compared to the unbound material (Sakr and Manke 1999; Saleh 2004).

The moduli of foam treated materials are generally lower than those of hot mix asphalt (HMA) (Loizos and Papavasiliou 2006), but can approach or exceed those of lime or cement treated materials (Sakr and Manke 1999). The properties are moisture sensitive as soaked specimens can have moduli 30-50\% lower than those of dry specimens (Sakr and Manke 1999). Moisture sensitivity can be reduced through the addition of $1-2 \%$ Portland cement (Bissada 1987; Nataatmadja 2002; Saleh 2004).

The work presented in this paper forms part of a larger project aimed at investigating the feasibility and potential applications of the foamed bitumen stabilisation technique in New Zealand, in particular as a means of 150 improving marginal quality aggregates and promoting its use in urban areas (Saleh and Herrington 2003; Saleh 2004).

\section{Laboratory testing}

The University of Canterbury' MATerials Testing Apparatus (MATTA) capable of undertaking both resilient modulus testing and permanent deformation testing was used. The triaxial test was carried out to measure the resilient modulus for the untreated unbound materials and those stabilised with cement, lime and foam bitumen stabilised mixes.

For the HMA, the Universal Testing Machine (UTM) provided with temperature control chamber (test temperature was kept at $25^{\circ} \mathrm{C}$ ) was used to determine the resilient modulus using the indirect repeated test, see figure $1 \mathrm{~b}, \mathrm{c}$. The details of the test procedures, protocols and results are fully discussed by the author somewhere else (Saleh and Herrington 2003; Byers et al. 2004; Saleh 2004).

Table 1 shows the resilient moduli for the eight stabilisation alternatives in addition to the HMA. Figure 2 shows the triaxial resilient modulus of the foam stabilised mix with $2.0 \%$ cement as a function of the bulk stress. It is clearly obvious from figure 2 that foam stabilised mixes will behave as a nonlinear material similar to unbound materials.

\section{Pavement thickness design}

In this analysis, the Multi-Layer Linear Elastic computer program CIRCLY was used for the pavement design (Wardle 1977). The Austroad mechanistic-empirical pavement design method was used in this pavement design exercise (Austroads 2004), in which the subgrade resilient modulus, $M_{\mathrm{r}}$, was assumed to be $50 \mathrm{MPa}$.

Figure 3 shows dual tyres of the standard axle load $(80 \mathrm{kN})$, each tyre carrying a $20 \mathrm{kN}$ load with a tyre pressure of $750 \mathrm{kPa}$, and a distance between the two tyres of $330 \mathrm{~mm}$. The equivalent single axle loads (ESAL) during the design period were assumed to be $5 \times 10^{6}$ ESAL. In all the design alternatives, a $200 \mathrm{~mm}$ thick subbase course of marginal materials with a resilient modulus value of $200 \mathrm{MPa}$ was used. In this design method both the unbound materials and subgrade were assumed to be anisotropic with a degree of anisotropy of 2 (i.e. $\left(E_{v} / E_{h}=2\right)$. The nonlinearity of the unbound base and subbbase was accounted for through sub layering regime programmed in the Circly software. The asphalt pavement was designed for both fatigue and subgrade rutting according to the transfer functions shown in equations (1) and (3). The foam stabilised base and other stabilisation alternatives were designed as unbound materials using subgrade vertical strain criterion shown in equation (3). The thickness of the pavement structure, $h$, was calculated according to the Austroads design method using each of the materials listed in table 1. Table 2 shows the required thickness of the pavement structure. The transfer functions used in the analysis are shown below, equations (1) and (3) (Austroads 2004).

\subsection{Fatigue life transfer functions for hot mix asphalt mix}

$$
N_{f}=\left[\frac{6918 *\left(0.856 * V_{\mathrm{b}}+1.08\right)}{S_{\mathrm{mix}}^{0.36} * \mu \varepsilon}\right]^{5} \ldots
$$

where: $V_{\mathrm{b}}$, percentage of bitumen by volume and can be determined from this equation

$$
\% V_{\mathrm{b}}=\frac{\% P_{\mathrm{b}} * G_{\mathrm{mb}}}{G_{\mathrm{b}}} \ldots
$$

where: $P_{\mathrm{b}}$, percentage of bitumen by total weight of mix; $G_{\mathrm{mb}}$, bulk specific gravity of the compacted mix; 
$G_{\mathrm{b}}$, specific gravity of bitumen; $S_{\text {mix }}$, stiffness of the mix (MPa); $\mu \varepsilon$, tensile strain at the bottom of the HMA (microstrains)

\subsection{Permanent deformation of subgrade}

$$
N_{f}=\left[\frac{9300}{\mu \varepsilon}\right]^{7.0}
$$

These assumptions have been made in the analysis:

- $P_{\mathrm{b}}$ for HMA design is $5.5 \%$ and $G_{\mathrm{mb}}=2.3$, therefore, $V_{\mathrm{b}}=12.4 \%$.

\section{Cost analysis of different alternatives}

Regarding the cost analysis, these assumptions have been made based on prices given by local contractors in both Christchurch and Auckland.

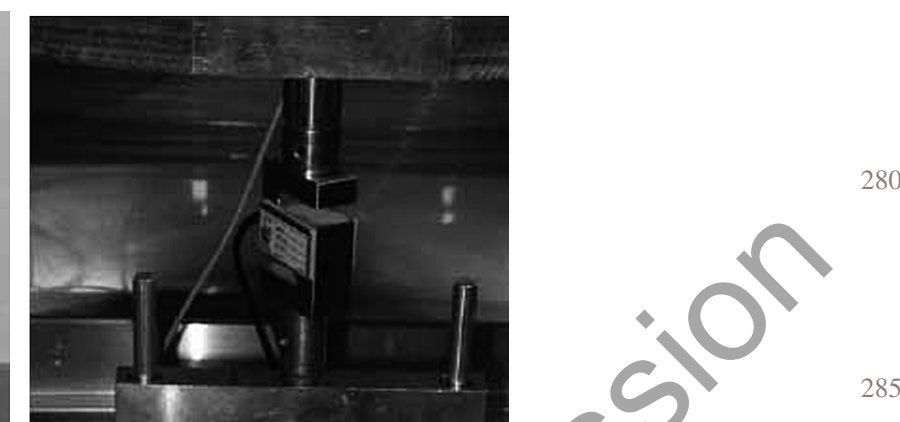

- The cost of HMA at $100 \mathrm{~mm}$ depth or more and an area of $1000 \mathrm{~m}^{2}$ (within $10 \mathrm{~km}$ from the mixing plant and assuming no traffic control), is $\$ 135.00 /$ tonne including supply, laydown and compaction.

- For unbound AP-20 (all passing $20 \mathrm{~mm}$ sieve) material at $100 \mathrm{~mm}$ depth and an area of $1000 \mathrm{~m}^{2}$ (within $10 \mathrm{~km}$ from the depot and assuming no traffic control), the cost is $\$ 40.00 /$ tonne including supply, laydown and compaction.

Table 1. Typical resilient moduli for various stabilisation alternatives.

\begin{tabular}{lc}
\hline Mix & Average $M_{\mathrm{r}}(\mathrm{MPa})$ \\
\hline Slag & 420 \\
Basalt & 340 \\
Greywacke & 380 \\
Greywacke $+1.5 \%$ emulsion & 337 \\
Greywacke $+2 \%$ lime & 484 \\
Greywacke $+4 \%$ lime & 600 \\
Greywacke $+2 \%$ cement & 900 \\
Premium quality greywacke $+3.5 \%$ foam & 1000 \\
bitumen $+2.0 \%$ cement & \\
Hot mix asphalt & 3000 \\
\hline
\end{tabular}




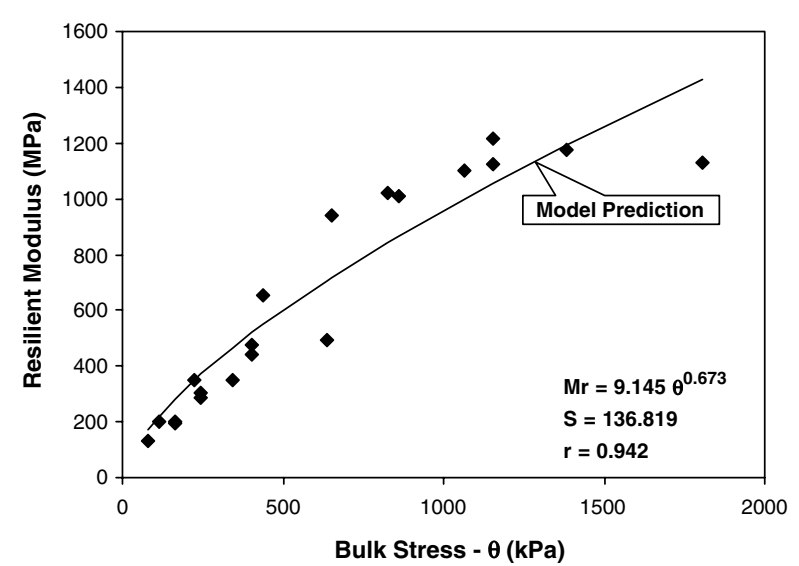

Figure 2. Relationship between resilient modulus of foam stabilised mix and bulk stress.

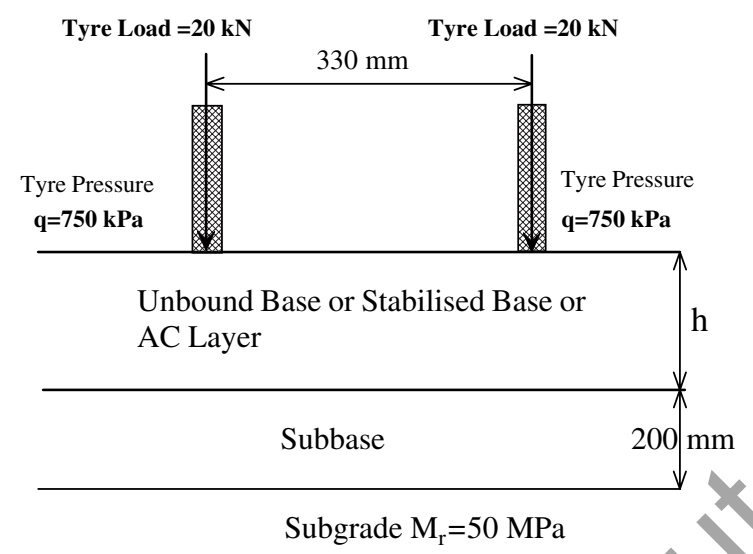

Figure 3. Pavement thickness and applied loads used in the pavement design method for comparing the different stabilisation methods.

- For lime-stabilised AP-20 (same details as above), the cost is $\$ 45.00 /$ tonne for $2 \%$ lime and $\$ 47$ for $4 \%$ lime, including supply, laydown and compaction.

- For cement-stabilised AP-20, (same details as above), the cost is $\$ 52.00 /$ tonne including supply, laydown and compaction.

- For foamed bitumen-stabilised AP-20, the price is $\$ 55 /$ tonne including allowance for addition of up to $10 \%$ virgin aggregate, fines correction, up to $1 \%$ cement, $3.5 \%$ foam, and surface preparation for surfacing.

- For marginal aggregates stabilised with about 3.5\%, the cost is $\$ 50.00 /$ tonne including transportation, laydown and compaction.
- If chipseal surfacing is to be used the cost is $\$ 4.00 / \mathrm{m}^{2}$. The cost for chipsealing a one lane-Km is $\$ 14,000$. This value is added to all alternative costs except the HMA alternative.

- For the subbase materials, the cost per tonne is $\$ 20$ 390 including transportation and laydown and compaction. The cost of the sub-base construction is $\$ 23,800$ per lane-km. This value is added to all alternative costs.

- In the analysis the lane width was assumed to be $3.5 \mathrm{~m}$.

The above prices do not include goods and service tax (GST).

Table 2 compares the thickness design and the capital cost of the various alternatives. Note that the analysis undertaken at this stage is based on the capital cost because of the lack of data about the performance of each stabilization method. However, if maintenance and user costs during the life of each method were considered, this would significantly impact the analysis.

The thickness design for the all alternatives except HMA was based on rutting, where the maximum compressive strain on the top of the subgrade layer was calculated and the transfer function given by equation (3) was used to determine the rutting life of the pavement. For asphalt concrete materials, the thickness design was based on the fatigue of the asphalt layer and therefore the tensile strain at the bottom of the asphalt layer was calculated and the transfer function given by equation (1) was used to determine the fatigue life. In addition to fatigue, the compressive strain at the top of subgrade layer was used to calculate the rutting of the pavement.

By comparing the cost of the different methods, as depicted in figure 4 , the capital cost of foamed bitumenstabilised base course is nearly similar to the cement stabilisation at $2.0 \%$. Adding the advantage of foam stabilisation such as the short time delay for traffic and other environmental benefits will make the foam stabilisation an attractive technique. On addition, it is expected that the cost of foamed bitumen stabilisation might decrease considerably with gaining more experience in this area, and when more contractors start to adopt this technique in New Zealand.

It is also obvious that this technique is much cheaper than HMA and it is expected to provide reasonable performance.

Table 2. Pavement thickness design (costs are \$NZ excluding gst).

\begin{tabular}{|c|c|c|c|c|c|c|c|c|}
\hline $\begin{array}{l}\text { Design } \\
\text { alternative }\end{array}$ & Mix & $\begin{array}{c}\mathrm{M}_{\mathrm{r}} \\
(\mathrm{MPa})\end{array}$ & $\begin{array}{c}\text { Thickness } \\
h(\mathrm{~mm})\end{array}$ & $\begin{array}{l}\text { Quantity per } \\
\text { lane- }-\mathrm{km} \\
\left(\mathrm{m}^{3}\right)\end{array}$ & $\begin{array}{l}\text { Unit } \\
\text { weight } \\
\left(\mathrm{t} / \mathrm{m}^{3}\right)\end{array}$ & $\begin{array}{l}\text { Quantity per } \\
\text { lane- }-\mathrm{km} \\
\text { (tonne) }\end{array}$ & $\begin{array}{l}\text { Cost per } \\
\text { tonne } \\
(\$ N Z)\end{array}$ & $\begin{array}{l}\text { Cost per lane-km } \\
\text { including sub-base } \\
\text { course and chipseal } \\
\text { surfacing ( } \$ \mathrm{NZ})\end{array}$ \\
\hline 1 & Slag & 420 & 245 & 894 & 2.0 & 1789 & 40 & 110960 \\
\hline 2 & Basalt & 340 & 255 & 931 & 2.0 & 1862 & 40 & 113880 \\
\hline 3 & Greywacke & 380 & 250 & 913 & 2.0 & 1825 & 40 & 112420 \\
\hline 4 & $2 \%$ Lime & 484 & 240 & 876 & 2.0 & 1752 & 45 & 118260 \\
\hline 5 & 4\% Lime & 599 & 235 & 858 & 2.0 & 1716 & 47 & 120049 \\
\hline 6 & $2 \%$ Cement & 898 & 235 & 858 & 2.3 & 1973 & 52 & 142007 \\
\hline 7 & Foam stabilised & 1000 & 235 & 858 & 2.3 & 1973 & 55 & 147925 \\
\hline 9 & HMA & 3000 & 230 & 840 & 2.3 & 1931 & 135 & 285485 \\
\hline
\end{tabular}




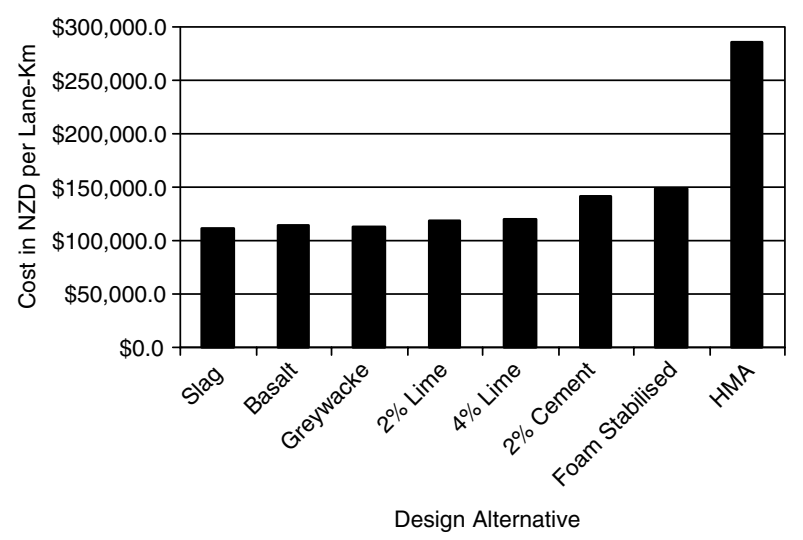

\section{Conclusions and recommendations}

A cost-analysis exercise comparing the cost of eight different stabilisation alternatives in addition to HMA was made. The results of this analysis showed that foamed bitumen stabilisation using high quality aggregates and about $2 \%$ cement is yery competitive for unbound materials because a reduced layer thickness is required. Because quantitative data are lacking environmental benefits and road user effects such as vehicle operating costs, or maintenance costs arising from various stabilisation methods, only capital cost of the different alternatives were considered rather than the life cycle cost which is more accurate measure of the economic value of the different alternatives. From the literature reviewed very likely such factors would serve to increase the competitiveness of the foamed bitumen stabilisation method relative to other alternatives. Because of the limited information about constitutive models and transfer functions of the foamed bitumen-stabilised mixes, the analysis was carried out assuming that the behaviour of the foamed bitumen material is similar to that unbound materials.
Based on this study foamed bitumen stabilisation appears to be cost-competitive alternative to those methods traditionally used in New Zealand. The technique appears to offer significant advantages in terms of speed of construction and less disruption to road users during construction.

\section{Acknowledgements}

The author would like to thank Transfund New Zealand for its financial support that has made this research possible. I also would like to express my appreciation to the Department of Civil Engineering, University of Canterbury, which has provided an intellectually stimulating environment in which to work.

\section{References}

Australian Stabihisation Industry Association Ltd (ASIA), Selection of Stabilisation Methods for Roadworks, Supplementary Notes to the Austroads Guide to Stabilisation in Roadworks, 2000 (Australian Stabilisation Industry Association).

Austroads, Pavement Design: A Guide to the Structural Design of Road Pavements, 2004 (Austroads: Australia).

Bissada, A.F., Structural response of foamed-asphalt-sand mixtures in hot environments. Transp. Res. Rec. J. Transp. Res. Board, 1987, No. $1115,134-149$.

Bowering, R.H. and Martin, C.L., Foamed bitumen production and application of mixtures: evaluation and performance of pavements. J. Assoc. Asphalt Paving Technol. (AAPT), 1976, 453-477.

Byers, C., Saleh, M.F. and Pidwerbesky, B.D., Evaluation of melter slag as a base course material. Int. J. Pavement Eng., 2004, 5(4), 193-199.

Csanyi, L.H., Foamed Asphalt in Bituminous Paving Mixtures, Highway Research Records No. 160, pp. 108-122, 1957 (National Research Council: Washington DC).

Csanyi, L.H., Foamed asphalt for economical road construction. Civ. Eng., 1962, 32(6), 62-69.

Hudson, K.C., Stabilisation for New Zealand Roads: A Review, Transit New Zealand Research Report No. 64, 1996 (Transit New Zealand: Wellington).

Jenkins, K.J., Van de Ven, M.F.C. and de Groot, J.L.A., Characterisation of foamed bitumen. 7th Conference on Asphalt Pavements for Southern Africa, pp. 1-18, 1999.

Loizos, A. and Papavasiliou, V., Estimation of certain foamed asphalt layer properties of cold in-place recycling. 85th Annual Meeting of Transportation Research Board, CD compendium, 2006.

Muthen, K.M., Foamed Asphalt Mixes, Mix Design Procedure, Report No. CR-98/077, 1999.

Nataatmadja, A., Foamed bitumen mix: soil or asphalt? 9th International Conference on Asphalt Pavements, p. 11, 2002.

Ruckel, P.J., Acott, S.M. and Bowering, R.H., Foamed-asphalt paving mixtures: preparation of design mixes and treatment of test specimens. Transp. Res. Rec. J. Transp. Res. Board, 1983, No. 911, 88-95.

Sakr, A.H. and Manke, P.G., Innovations in Oklahoma foamix procedures. Transp. Res. Rec. J. Transp. Res. Board, 1999, No. 1034, 26-34.

Saleh, M. and Herrington, P., Foamed Bitumen Stabilisation for New Zealand roads, Transfund New Zealand Research Report No. 250, p. 86, 2003.

Saleh, M., Detailed Experimental Investigation for Foamed Bitumen Stabilization, Transfund New Zealand Research Report No 258, p. 68, 2004.

Wardle, L.J., Program CIRCLY, User's Manual, Geomechanics Computer Program Number 2, 1977 (Division of Applied Geomechanics, Commonwealth Scientific and Industrial Research Organisation: Melbourne). 